\title{
An Analysis on the Path to Merging Quality Education with Exam-oriented Education Effectively: From the Aspect of the Symbiosis Theory
}

\author{
Hongxia Zhang \\ Zhengzhou University of Industry Technology , Zhengzhou, Henan Province. 451150.
}

Keywords: Symbiosis theory; Quality education; Exam-oriented education

\begin{abstract}
As two different modes of education, quality education and exam-oriented education have been discussed and debated continuously in educational practices. Based on the view of symbiosis theory, this essay analyses the essence and effect of these two different modes of education and concludes the shortcomings and advantages of them, by which comes up with the basic idea and methods to combine quality education with exam-oriented education in practice.
\end{abstract}

\section{Introduction}

In the Compulsory Education Law of the People's Republic of China, revised in 2006, it is provided that the compulsory education in our country must conduct relative educational policies strictly, keep pace with the quality education, to bring up qualified personnel talents, who are suitable for the construction of society, for the whole country and society. As the legalization of compulsory education, the idea of which has been rooted in people's mind gradually. Meanwhile, a series of nationwide mass bottom-to-top education revolutions are carried out, whose center is quality education. However, when it comes to the essence, contains, pros and cons of these two kinds of educational modes, there are always some arguments. The idea of quality education supremacy showed an unpleasant effect in practice, which becomes an obstacle to the nationwide spreading of quality education in a certain degree. Therefore, a scientific and objective analysis on the essence, contains, characteristics, methods and effects of quality education and exam-oriented education, and a research on the inevitable link between these two modes are of vital significance and practical meaning to the implementation of nationwide quality education.

\section{The Analysis on the Essence of Quality Education and Exam-oriented Education}

Quality education is a kind of educational mode aiming at leveling up the comprehensive quality of students, including education of their knowledge qualities, moral qualities, behavior qualities, physical and mental health, among which the core is education, and cultivating them to become comprehensively developed individuals. As a comparative advanced mode of education, quality education owns characteristics of open and wide. It opens to every students, emphasizing and developing their interests and hobbies.

Exam-oriented education is a kind of educational mode judging and selecting students mainly by objective exams according to the curriculum, which is based on contains of classes. Compared with quality education, exam-oriented education ignores individuals' differences, so that it cannot activate all of students' interests and hobbies, but its core aim is still educating and cultivating personnel talents.

Seeing from the essence of quality education and exam-oriented education, quality education thinks highly of comprehensive development and exam-oriented education values the mastery of cultural knowledge and the development of intelligence more, but their aims are same: to cultivate personnel talents for the construction of socialism. In this point, they're the same as each other. 


\section{An Analysis on the Characteristics of Quality Education and Exam-oriented Education in Practice}

As an advanced and modern society-suited educational mode, quality education have outstanding characteristics in practice, mainly showed as openness, extensiveness, sustainability, and s.

Its extensiveness is showed in the aspects of objects. Analyzed in a narrow sense, the objects of exam-oriented education include teachers, parents, administrations besides students. They are all objects during the process of implementing quality education.

The sustainability means that under a certain social development background, the educated students will change themselves along with the constant change of the state of their body, mind and adaptivity to society, the contains and forms of quality education in different period of their changing is also different. In primary school, teachers teach students to study and live, while in university, professors highlight the adaptation skills to society, and achieving oneself. The targets of different steps are clear. The characteristic of sustainability is one of its notable features.

The root of quality education is improving students' comprehensive quality, so the implementing environment of it is not restrained in the school education, but also family education, society education, surroundings education, and so on, they are good platforms as well, which result in the implementing environment of quality education should be a open, dynamic-balanced one. Family is the fundament to quality education; society, the back; school, the key; open environment, the guarantee.

The uncertainty of educational effect feedback of quality education is presented in the individuals' differences. Intelligence, strength, mind, and adaptivity to society, etc. are closely connected with individuals. In the aspect of effect feedback, quality education has obvious uncertainties and incomparability. For intelligence, learning something and knowing how to learn are two different state of studying, however, the feedback of quality education fails to give a certain standard to confirm if a student is learning, or if a student knows how to learn. Besides, the implementation of quality education has differences between urban and rural areas, and between large cities and small cities, which is a main restraining feature bothering the feedback of quality education. A student living in rural area, who is regarded as a qualified and comprehensively developed student, may be considered to be the same or even worse than a student living in city, which is just because the uncertainty and incomparability of quality education, and it leads to unbalanced situation or even resistance during the process of implementing.

Compared with quality education, exam-oriented education is more unitive, unilateral, easy to control, and can get objective feedback.

This kind of education is characterized as unitive because of the unitive administration in practice. Under the leadership of educational administration, we use unitive curriculum, textbooks, and feedback system. The unitive exam-oriented education have more obvious advantages than quality education in the past for long, especially when it comes to human resource management, facility management and finance management, this kind of education mode saves a lot of energy and materials during its process. It has more comparability in the aspect of effect feedback, and gives a good standard for teachers to make comments about the quality of teaching.

Exam-oriented education is unilateral compared with quality education, because exam-oriented education thinks highly of students' knowledge structure, and their intelligence development, but thinks lowly of their mental health, adaptivity to society and so on compared with quality education. Examoriented education ignores students' subjective initiative in some extent, and fails to catch up with the promotion of other qualities of a student.

Exam-oriented education is considered as easy to control, for the mode of exam, and the curriculum and textbooks are united in practice, so the exam is unitive, too. Both the educational administration and the school management department can manage efficiently according to corresponding principles and rules in advance. When it comes to human resource management, facility management and finance 
management, this kind of education mode saves a lot of energy and materials during its process. It has more comparability in the aspect of effect feedback.

In the evaluation of teaching effectiveness, exam-oriented education mode is mainly reflected by the form of examination, which has been criticized. To some extent, it also has its positive significance. In terms of the objectivity of evaluation, the unified examination has a strong conviction than the feedback of quality education. In terms of the comparability, evaluation of the examination can be less effected by the environment, economic and so on. There is a strong fair selection of personnel, and positive effect that cannot be replaced by other modes.

\section{Analysis on the Effective Fusion of Quality Education and Exam-oriented Education}

Objective and scientific education is the basis for the effective integration of the two modes of education. Both exam-oriented education and quality education are the kind of modes that emerge step by step in accordance with the needs of social development and do not exist independently of the society. Quality education and exam-oriented education all have their own distinctive features in the practice of specific education. At the same time, both of them have their advantages and disadvantages. Only in objective and scientific understanding, can we combine the advantages of the two modes of education effectively and give full play to their educational role in the teaching process.

Education system reform is the key to the effective integration of quality education and examoriented education. In the current period, education, especially compulsory education in our country has been faced with the formalization of quality education and the plight of exam-oriented education. In the specific education practice, quality education strengthens the openness and interaction of the classroom in order to further improve the hardware configuration of schools. We should by more computers and more books, but in the end, school education is still restrained by rankings and examination rankings of educational administrations at all levels, to determine the quality of teaching in schools. Quality education still survives difficultly in the exam-oriented education mode. In order to fully implement quality education, we should focus on the bold reform of education authorities, education authorities at all levels should focus on decentralization of education in schools within the framework of education and teaching guidelines, so that schools can have more autonomy on the selection of teaching materials, the choice of teaching content, the setting of curriculum and the standard of curriculum examination and so on, to give schools a certain degree of autonomy, so as to help form a variety of diverse content-rich teaching system and further stimulate teachers' subjective initiative and to promote the implementation of quality education.

Scientific and reasonable evaluation index system is the basis of effective integration of quality education and exam-oriented education. The quality of any kind of education mode cannot be separated from the final evaluation. The design of evaluation index directly guides the direction of teaching process. How to promote the full implementation of quality education and the scientific and reasonable evaluation index system plays a crucial role. The evaluation index of education must be based on the characteristics of the implementation of quality education and the development of education in the region to conduct scientific and objective analysis and formulation. We need to consider the proportion of qualitative assessment and quantitative assessment, so as to take into account the quality of education's uncertainty and the objectivity and unity of exam-oriented education. Only in this way, can we make quality education and exam-oriented education take their own advantages in the practice of specific education, promote the quality of education to be better implemented at the same time, and give an objective teaching and learning feedback.

The improvement of teachers' quality is the carrier of effective integration of quality education and exam-oriented education. As a subject of education, teachers play an important guiding role in specific education. Only when teachers understand the essential connotation of quality education and examoriented education correctly can teachers adopt appropriate teaching methods in first-line education, 
especially the implementation of quality education, which even demands more on teachers' professional ability and accomplishment. The traditional kind of text reading for half a day and the teaching methods of two chalk for a long time are certainly not suitable for the development of quality education. Therefore, the improvement of teachers' qualities, particularly their scientific and objective understanding to both quality education and exam-oriented education enables them to carry out quality education, and meanwhile use scientific and objective methods to analyze the feedback, which plays an important role of carrier in enhancing advantages of both educational modes and raise the quality of education.

\section{Conclusion}

In current situation, education is a kind of social resource to change destiny and life, and the society will continue to aggravate the competition for the quality of education, and the full implementation of quality education also faces various difficulties. Any kind of education mode has its advantages and disadvantages. In the process of education, there will not be simply a single kind of education mode. The effective integration of exam-oriented education and quality education can make up for its advantages and make up for its shortcomings, which is a key to the full implementation of quality education at present. Only when we fully base ourselves on the present situation of social development, with the concerted efforts of the government, society and schools, the education reform in our country can achieve greater development.

\section{Reference}

[1] A Report of The Fifth Session of the Twenty-fourth Conference of The Standing Committee of National People's Congress, Hearing from the Education Administration Chief Yuan Guiren Assigned by the National Congress on the Condition of Implementation of National Education Reform and Development of Long-term Planning Programs (2010-2020). The website: http://www.anhui.cc/news/20111229/275641.shtml.

[2] Unknown, Asking Zhong Qiquan: When Should We Announce the Failure of New Curriculum Reform [J], The Forum of People's Education, the Forum of curriculum, 2009(2)

[3] Yang Runyong, The Analysis on the Evaluation Problems During the Process of Implementing the Quality Education [J], Jiangxi Educational Research, 2006, (7)

[4] The group of "The concept, contains and relative theories of quality education", The Concept, Contains and Relative Theories of Quality Education [J], Educational Research, 2006, (2)

[5] Ye Lan, Introspect Clearly Again and Again: A Re-acknowledge on What Is Quality Education. [J], People's Education, 2007, (2) 